\title{
Effects of contact pressure, counter surface, and humidity on wear of soda-lime-silica glass at nanoscale
}

\author{
Hongtu He ${ }^{1}$, Seong H. Kim ${ }^{2}$, Linmao Qian ${ }^{1 *}$ \\ 1 Tribology Research Institute, National Traction Power Laboratory, Southwest Jiaotong \\ University, Chengdu 610031, P.R. China \\ ${ }^{2}$ Department of Chemical Engineering and Materials Research Institute, Pennsylvania State \\ University, University Park, Pennsylvania 16802, United States \\ * Corresponding author: linmao@swjtu.edu.cn
}

\begin{abstract}
:
The nanoscale friction and wear behaviors of soda-lime-silica (SLS) glass were studied using atomic force microscopy (AFM) using diamond (inert) and silica (reactive) tips in dry and humid environments. Depending on the contact pressure, counter-surface chemistry, and humidity, three distinct wear regimes were identified: mechanical wear, stress corrosion, and tribochemical wear. The mechanisms of material removal at these three wear regimes were proposed. These results provided insights into mechanical and mechanochemical wear mechanisms of the SLS glass at nanoscale, which will be useful to optimize tribological designs of functional and engineering glasses.
\end{abstract}

Keywords: soda-lime-silica glass, nanoscale wear; AFM; interfacial tribochemistry 


\section{Introduction}

Owing to its good mechanical, chemical and physical properties, soda-lime-silica (SLS) glass has attracted a lot of attentions in a wide range of advanced engineering and functional applications in aerospace, building, portable devices, etc [1]. All these applications require fine surface finish and dimensional accuracy that are often achieved by conventional grinding and polishing processes. If (sub)surface damages are created in glass during such processes, it would affect the function or service life of glass materials [2-4]. Therefore, in order to understand and control surface damage or material removal behavior, it is essential to study the friction and wear behavior of glass materials in ambient conditions.

Previous investigations indicated the water from the environment played a critical role in the damage process of soda-lime-silica (SLS) glass. For example, under normal indentation conditions, the mechanical properties of glass decreased when exposed in water vapor or liquid water conditions [5]. Under single lateral scratch conditions, a larger damage of SLS glass was observed as relative humidity $(\mathrm{RH})$ increased [6]. It has been attempted to explain these phenomena using the classical stress corrosion theory, which depicted that $\mathrm{H}_{2} \mathrm{O}$ molecules can facilitate the dissociation of the $\mathrm{Si}-\mathrm{O}-\mathrm{Si}$ network, assisting the crack propagation through silicate glass materials [7]. Recently, it was found the macroscale wear of fused quartz, borosilicate glasses and aluminosilicate glasses were consistent with the stress-corrosion theory, where there wear resistance decreased as RH increased. However, the SLS glass showed a decrease in wear as RH increased [8-10]. Through sodium ion $\left(\mathrm{Na}^{+}\right)$ redistribution at SLS glass surface upon thermal poling, it was found the $\mathrm{Na}^{+}$-depleted layer showed more wear as $\mathrm{RH}$ increased, while the $\mathrm{Na}^{+}$-gradient layer showed less wear at higher 
RH. Since the $\mathrm{Na}^{+}$leaching and the stress corrosion were competitive process, the leachable $\mathrm{Na}^{+}$ions at the SLS glass surface may play critical roles in the wear process. In a study of the counter-surface chemistry effect on the wear of SLS glass, it was found that in dry conditions, SLS glass was damaged mechanically regardless of counter-surface materials, creating a rough and deep wear track; while in humid conditions, the ball materials that were harder than the SLS glass were damaged [11]. This implied that mechanochemical reactions involving $\mathrm{H}_{2} \mathrm{O}$ and counter-surface played important roles in interfacial wear.

All prior experiments have been conducted with a macroscopic ball-on-flat tribometer, where the specific asperity contact areas and pressures were unknown. With atomic force microscopy (AFM), the applied load at the contact asperity could be controlled more precisely [12-14]. Thus, the nanoscale friction and wear test using AFM could be a pathway to obtain experimental data needed to understand the physical and chemical mechanisms of material damage of glass materials in humid environments. There are a few AFM studies on nanoscale wear. In a basic solution, the wear behavior of sodium trisilicate $\left(\mathrm{Na}_{2} \mathrm{O}-3 \mathrm{SiO}_{2}\right)$ glass by silicon nitride AFM tip appeared to occur through interfacial tribochemical reactions [15]. Upon scratched by a $\mathrm{CeO}_{2}$ particle attached to an AFM system, a Nd-doped phosphate laser glass also showed a wear pattern that could be explained by the stress-corrosion process [16]. The effects of applied load and sliding cycle on the friction and wear of SLS glass were studied using a diamond AFM tip and it was suggested that the mechanical wear dominated the surface wear behaviors of SLS glass [17]. However, this study focused on the substrate deformation during ploughing and shear cutting in the plastic regime. The surface deformation and wear behavior in the non-plastic regime have not been studies systematically. 
Overall, the physical and chemical mechanisms of nanoscale friction and wear of SLS glass are poorly understood [18].

In the present paper, we used AFM to study the effects of applied load, counter-surface chemistry, and humidity on wear of SLS glass. The experimental conditions tested in this work were summarized in Table 1: (1) scratch with a (non-reactive) diamond tip in a (non-reactive) vacuum environment; (2) scratch with a (non-reactive) diamond tip in a (reactive) humid environment; (3) scratch with a (reactive) $\mathrm{SiO}_{2}$ tip in a (reactive) humid environment. The comparison of experimental data clearly showed how dominant wear mechanism changes depending on the test condition.

\section{Experiments methods}

The glass substrates tested in this study were soda-lime-silica (float) glass samples with a thickness of $0.7 \mathrm{~mm}$ (cutting from float glass from Asahi Glass Company, Japan). Due to the manufacture process, the SLS float glasses have two sides: air-side and tin-side. In order to avoid complications due to tin contaminations, the air-side of soda-lime float glass was tested in the present paper. The root-mean-square roughness of the SLS glass substrate was measured as $0.07 \mathrm{~nm}$ over an area of $500 \times 500 \mathrm{~nm}^{2}$. All nanowear tests were performed by an AFM system equipped with an environmental control system and a relative humidity (RH) detector (HP22-A, Rotronic, Switzerland), as shown in Figure 1(a). More details of these systems could be found in a previous publication [19]. Two kinds of AFM tips were used: (i) a spherical $\mathrm{SiO}_{2}$ tip with a radius (R) of $1 \mu \mathrm{m}$ (Novascan Technologies, USA) and (ii) a cubic corner diamond tip with $\mathrm{R}=0.55 \mu \mathrm{m}$ (Micro Star Technologies, USA), as shown in Figure 
1(b). The spring constants of the cantilevers used in this study were $16 \mathrm{~N} / \mathrm{m}$ for the spherical $\mathrm{SiO}_{2}$ tip and $197 \mathrm{~N} / \mathrm{m}$ for the diamond tip. All nanowear tests were operated at $\sim 23^{\circ} \mathrm{C}$. The wear tests with the diamond tip (SLS glass/diamond interface) were performed in vacuum and $40 \% \mathrm{RH}$ conditions. The wear tests with the $\mathrm{SiO}_{2}$ tip (SLS glass $/ \mathrm{SiO}_{2}$ interface) were performed in $40 \% \mathrm{RH}$ condition. The variation of $\mathrm{RH}$ during the measurement was controlled within $2 \%$ from the set value. The sliding span of the reciprocating cycle was $500 \mathrm{~nm}$ with a sliding speed $2 \mu \mathrm{m} / \mathrm{s}$. The total number of sliding cycles was 400 . The topography of wear scars was imaged with AFM using a silicon nitride tip in vacuum. The silicon nitride tip had a nominal curvature of $20 \mathrm{~nm}$ and a nominal normal spring constant of $0.1 \mathrm{~N} / \mathrm{m}$ (MLCT, Veeco, USA). The scan size of the AFM image was $2 \times 2 \mu \mathrm{m}^{2}$. The dissipated energy was calculated by integrating the measured friction force over the sliding distance for each sliding cycle and then adding them for 400 sliding cycles.

\section{Experiment results}

\subsection{Nanowear behaviors of SLS glass upon a diamond tip in vacuum}

Figure 2 displayed the AFM images of the SLS glass surface scratched with a diamond tip in vacuum. A "hillock-like" protrusion was formed at SLS glass at lower load conditions (Figure 2(a) and (b)), which is different from a typical "trench-like" or "groove-like" wear scar with material removal. The height of the protrusion was $\sim 1.5 \mathrm{~nm}$ at an applied load of 20 $\mu \mathrm{N}$, it decreased to $\sim 1 \mathrm{~nm}$ when the applied load was increased to $30 \mu \mathrm{N}$. Under the applied load of $20 \mu \mathrm{N}$, the Hertzian contact width and indentation depth were estimated as $96 \mathrm{~nm}$ and $4.2 \mathrm{~nm}$, respectively. As the applied load increased to $30 \mu \mathrm{N}$, the contact width and depth 
increased to $110 \mathrm{~nm}$ and $5.5 \mathrm{~nm}$, respectively. The increase in wear width with increasing the load from $20 \mu \mathrm{N}$ to $30 \mu \mathrm{N}$ (Figure 2(a) and (b)) was consistent with this estimation.

Previous investigations reported that the hillock-like protrusion could be formed at silicon and quartz surfaces under nanoscale friction and wear testing [20]. For the hillock formation on silicon, the main reason was speculated to be mechanical deformation of the subsurface into an amorphous structure [21]. In the case of quartz surface, the lattice distortion and dislocations at subsurface were the main reason the hillock formation [20]. Although the subsurface deformation of SLS glass was not characterized yet, it was speculated that under sliding contact conditions, the subsurface Si-O-Si network of the SLS glass could be strained due to the normal and shear stresses; this might distort the distance or angle of the Si-O bonds, which could lead to the local expansion of molar volume [21].

When the applied load was increased to $40 \mu \mathrm{N}$, the hillock-like protrusion was not prominent anymore; instead a small groove with a $\sim 0.2 \mathrm{~nm}$ depth was formed (Figure 2(c). Some pile-ups of debris were also formed along the wear track. Thus SLS glass materials were removed at this high load condition. When the sliding cycles (N) were decreased to 200, the groove pattern was smaller ( 0.13 nm deep) (data not shown). Overall, the data in Figure 2 implied that the mechanical removal of the SLS glass material occurs only when the applied load is high enough.

\subsection{Nanowear behavior of SLS glass upon a diamond tip in humid air}

When water molecules were involved at the diamond tip/SLS glass interface, the nanowear pattern changed. As displayed in Figure $3(\mathrm{~d})$, under the same applied load $(30 \mu \mathrm{N})$ 
as in Figure 2 (b), the nanowear pattern created in humid air was much deeper than that in vacuum. In humid air, the wear scar (topographic depression) was $\sim 1 \mathrm{~nm}$ deep and $\sim 300 \mathrm{~nm}$ wide. As the applied load was decreased to $20 \mu \mathrm{N}$, the wear depth decreased to $\sim 0.8 \mathrm{~nm}$, and the wear width did not change significantly (Figure 3(c)). Since those tests were conducted at the same applied load and sliding speed as in the vacuum test condition using the same counter-surface (diamond tip), the deeper wear must be the consequence of the water-involved mechanochemical reactions at the sliding interface. It should be noted that the hillock-like protrusion with $\sim 1 \mathrm{~nm}$ height was still observed in humid conditions when the applied load was very low as shown in Figure 3(a).

\subsection{Nanowear behavior of SLS glass upon a silica tip in humid air}

The material removal behaviors depend not only on the test environment and substrate materials, the counter surface chemistry also plays a critical role [22]. Figure 4 showed the nanowear pattern of the SLS glass when rubbed with a silica tip. Unlike the diamond surface, silica tip can be involved in chemical reactions with water during the sliding. When the applied load was lower than $1.5 \mu \mathrm{N}$, there was no discernable damage within the spatial resolution of AFM (Figure 4 (a) and (b)). However, when the applied load was increased to 2 $\mu \mathrm{N}$, there was substantial removal of substrate materials leaving a $\sim 4 \mathrm{~nm}$ deep and $\sim 280 \mathrm{~nm}$ wide wear mark (Figure 4 (c)); as the applied load increased to $3 \mu \mathrm{N}$, the wear depth and width increased to $\sim 6 \mathrm{~nm}$ and $\sim 420 \mathrm{~nm}$, respectively (Figure 4 (d)).

\section{Discussion}




\subsection{Effect of tribochemistry on the friction coefficient}

Figure 5(a) compared the friction coefficient of SLS glass rubbing with a diamond tip in vacuum and humid conditions. In vacuum, the friction coefficient was $\sim 0.3$ and it did not vary significantly with applied load and sliding cycles. The friction coefficient decreased to $\sim 0.18$ when nanowear tests were performed in humid air, and it did not vary with applied load and sliding cycles. Using a reciprocating ball-on-flat tribometer, it was found that the friction coefficient would be $\sim 0.2$ as long as solid materials were covered by adsorbed molecules, regardless of bulk mechanical properties of tested materials [23]. Thus, the reduction of friction coefficient in humid air implied that at the diamond/SLS glass interface, the adsorbed water molecules could act like a molecular lubricant or a physisorbed lubricant.

The reduction of friction upon introduction of water also mean that the dissipation of the interfacial shear energy through the SLS subsurface decreased; this might be the reason that the hillock-like protrusion by subsurface deformation was reduced in humid conditions compared to the vacuum test. However, this does not mean that the SLS surface would be protected completely from damage. The mechanical energy transferred into SLS glass in the presence of reactive molecules such as water could induce new chemical reactions, which will be discussed in Section 4.2 [24].

In the case of the silica tip in humid conditions, the friction coefficient varied in a more complicated way with changing the applied load and sliding cycle. As shown in Figure 5 (b), when the applied load did not cause discernable wear of glass substrate, the friction coefficient was relatively stable and low at $\sim 0.3$, and it did not vary significantly with the sliding cycles. When the applied load was increased causing discernable wear of glass 
substrate, the friction coefficient was higher than 0.7 .

It is noted that the friction coefficient $(\sim 0.3)$ of the silica tip in humid air was higher than that of the diamond tip $(\sim 0.2)$; this discrepancy implies that the lubrication effect of the adsorbed water is negligible at the silica/SLS glass interface [22,23]. It is also very intriguing to see that the friction of the silica tip was much higher when the SLS glass surface was damaged, compared to the negligible wear case at low applied loads. Most importantly, the wear by the silica tip in humid air occurred at contact pressures much lower than the diamond tip case. More details of this case will be discussed in Section 4.3.

\subsection{Effect of adsorbed water on the mechanochemical reactions at SLS glass surface}

Not only the water adsorption, but also the counter-surface chemistry could significantly affect the nanoscale wear at solid interfaces. In the case of diamond tip, the chemical reactivity of tip was very low, so the effect of counter-surface chemistry on the nanowear of SLS glass could be ignored. Thus, the comparison of the wear behaviors by the diamond tip in vacuum and humid conditions could be a good system to reveal the mechanochemical effects of water when shear is applied by the inert counter-surface. The stress-corrosion behavior is a well-known phenomenon for silicate glasses [25]. This theory depicted that molecules possessing proton donors and lone-pair electrons such as $\mathrm{H}_{2} \mathrm{O}$ can undergo dissociative chemisorption across the $\mathrm{Si}-\mathrm{O}$ bond, and this process is facilitating under tensile stress, as shown in Figure 6 (a) and equation (1) [7]:

$$
\mathrm{Si}-\mathrm{O}-\mathrm{Si}_{\text {(glass) }}+\mathrm{H}_{2} \mathrm{O} \rightarrow 2 \mathrm{SiOH}
$$


The data presened in Figures 2 and 3 are consistent with the stress corrosion theory.

However, in the case of silica tip, the effect of counter-surface chemistry could not be ignored. Through experiments and simulations, it was suggested that chemical bonds bridging between substrate and counter surface could be formed, and their formation and dissociation played a predominant role on the nanowear behaviors of material $[22,26]$. Since both silica tip and SLS glass surface contained Si-OH groups in humid air, the $\mathrm{Si}_{\text {(tip) }}-\mathrm{O}-\mathrm{Si}_{\text {(substrate) }}$ bond bridge could be formed at the silica tip/SLS glass interface through a dehydration and condensation reaction, as shown in equation (2):

$$
\mathrm{Si}-\mathrm{OH}_{\text {(glass) }}+\mathrm{Si}-\mathrm{OH}_{\text {(tip) }} \rightarrow \mathrm{Si}_{\text {(tip) }}-\mathrm{O}-\mathrm{Si}_{\text {(glass) }}+\mathrm{H}_{2} \mathrm{O}
$$

Then, the tensile force applied to the $\mathrm{Si}_{\text {(tip) }}-\mathrm{O}-\mathrm{Si}_{\text {(substrate) }}$ bond during the interfacial shear could faciliate the dissociation of the subsurface $\mathrm{Si}-\mathrm{O}$ bond [22], as shown in equation (3):

$$
\mathrm{Si}_{\text {(glass) }}-\mathrm{O}-\mathrm{Si}_{\text {(glass) }}+\mathrm{H}_{2} \mathrm{O} \rightarrow 2 \mathrm{SiOH}_{\text {(glass) }}
$$

Thus, in the case of glass/silica interface, not only the stress-corrosion, but also the tribochemical process involving counter-surface and water molecules could take place at the sliding interface.

\subsection{Transition from mechanical wear to stress corrosion to tribochemical} wear

In the previous sections, we considered three different wear mechanisms - purely mechanical, stress corrosion due to water and shear stress imposed by the inert counter surface, and tribochemical reactions involving water and reactive counter-surface chemistry. In this section, we will discuss the role of mechanical load and shear in each process. In our 
experiments, the maximum contact pressure could be estimated using the Derjaguin-Muller-Toporov (DMT) contact mechanics model:

$$
P_{c}=\frac{3}{2 \pi}\left[\frac{K^{2}}{R^{2}}\left(F_{n}+F_{a}\right)\right]^{1 / 3}
$$

The critical contact pressure $\mathrm{P}_{\mathrm{y}}$ for the initial yield of SLS glass could be estimated in the following steps. Because the Poisson ratio of SLS glass is 0.23 , the principle shear stress $\tau_{\mathrm{c}}$ could be estimated by [27]:

$$
\tau_{c}=0.3 P_{c}
$$

and the critical contact pressure $\mathrm{P}_{\mathrm{y}}$ for plastic deformation could be estimated from the Tresca yield criterion $\left(\tau_{c}\right)_{\max } \leq 0.5 \sigma_{y}$ :

$$
P_{y}=\frac{1}{0.3}\left(\tau_{c}\right)_{\max } \leq \frac{1}{0.3} 0.5 \sigma_{y}=1.67 \sigma_{y}
$$

Because the yield stress $\sigma_{\mathrm{y}}$ of SLS glass is $4 \mathrm{GPa}$ [28], the critical contact pressure $\mathrm{P}_{\mathrm{y}}$ for plastic deformation is estimated to be $\sim 6.5 \mathrm{GPa}$.

In the wear tests of SLS glass/diamond and SLS glass/silica interfaces, the maximum contact pressure $\mathrm{P}_{\mathrm{c}}(3.5 \mathrm{GPa})$ was much lower than the critical contact pressure $\mathrm{P}_{\mathrm{y}}(6.5 \mathrm{GPa})$; thus, the contact between SLS glass and the AFM tip must be elastic. As displayed in Figure 7, the threshold contact pressure for the material removal was $\sim 3.4 \mathrm{GPa}$ for the diamond tip in vacuum, which was lower than $\mathrm{P}_{\mathrm{y}}(6.5 \mathrm{GPa})$. This was quite different from the wear behavior observed for the crystalline silicon and quartz substrates; when scratched with a diamond tip in vacuum, these crystalline substrates did not show 'material removal' as long as the contact pressure was lower than their $\mathrm{P}_{\mathrm{y}}$ values [22]. The fact that the SLS glass is damaged even though the contact pressure was lower than $\mathrm{P}_{\mathrm{y}}$ of glass suggested that the SLS 
glass surface had defects. It is known that the hydrous species $\left(\mathrm{Si}-\mathrm{OH}\right.$ and $\left.\mathrm{H}_{2} \mathrm{O}\right)$ in the subsurface region could lower the strength of the SLS glass [29].

When the wear test was performed with the diamond tip in humid conditions, the threshold contact pressure was reduced to $\sim 2 \mathrm{GPa}$, compared to the vacuum case $(\sim 3.5 \mathrm{GPa})$. This could be attributed to the stress corrosion mechanism discussed in Section 4.2.

When the chemically-inert diamond tip was replaced with the silica tip containing surface hydroxyl groups, the critical contact pressure in humid conditions decreased further to $\sim 0.72 \mathrm{GPa}$. This supports that the material damage and removal are dominated by the chemical reactions involving both solid surfaces as well as water molecules such as formation of $\mathrm{Si}_{\text {(tip) }}-\mathrm{O}-\mathrm{Si}_{\text {(substrate) }}$ bridge bonds and their dissociations during the interfacial sliding. During the sliding process, the interfacial $\mathrm{Si}_{(\text {tip) }}-\mathrm{O}-\mathrm{Si}_{\text {(substrate) }}$ bond bridge could increase the strained or stretch of the subsurface $\mathrm{Si}-\mathrm{O}-\mathrm{Si}$ bond; the strained $\mathrm{Si}-\mathrm{O}-\mathrm{Si}$ bond is expected to be the most reactive or vulnerable sites [30]. At low applied load conditions, the mechanical stress might not be high enough to induce the dissociation of substrate $\mathrm{Si}-\mathrm{O}$ bonds. As the applied load increased, the rupture of interfacial bonds could cause the surface damage of SLS glass, and the surface materials could be removed by the reciprocated sliding contact conditions. MD simulations suggested that the activation barrier of hydrolysis reaction decreased as the applied stress increased [31]. With the interfacial tribochemistry, the activation energy for the substrate bond-breaking could be lowered [32,33].

\section{Conclusion}

In present paper, we used an environment-controlled atomic force microscope (AFM) to 
study the origin of nanowear of soda-lime-silica (SLS) glass by comparing the friction and wear of SLS glass under vairous reactive gas and reactive counter-suface conditions. The main conclusions could be summarised as follows:

(1) When the SLS glass substrate was rubbed with a chemically-inert diamond tip in an inert environment (vacuum), the hillock-like prostrusion was formed at the glass surface under lower contact load conditions, rather than surface material removal. The wear appeared to start at a contact pressure of $\sim 3.4 \mathrm{GPa}$, which was lower than the critical yield strength of SLS glass. This could be attributed to the presence of surface defects such hydrous species at the glass surface.

(2) When the SLS glass substrate was rubbed with a chemically-inert diamond tip in the presence of reactive gas (water vapor), the threshold stress for the surface material removal decreased to $\sim 2 \mathrm{GPa}$. This decrease could be attributed to stress corrosion reactions of the silicate network in the presence of water and shear stress.

(3) When the SLS glass substrate was rubbed with a chemically-reactive silica surface in the presence of reactive gas (water vapor), the threshold stress for the surface material removal decreased further to $\sim 0.7 \mathrm{GPa}$. This was attributed to tribochemical wear reactions involving the $\mathrm{OH}$ groups at both subtrate and counter-surface and the adsorbed water molecules at the sliding interface.

\section{Acknowledgement}

This work was supported by the National Science Foundation of China (Grant No. 91323302, 51375409, 51175441). HH was also very thankful for the Funding Project from Graduate 
School of Southwest Jiaotong University (YC201402103). SHK was supported by the National Science Foundation (Grant No. DMR-1207328). The authors acknowledged Asahi Glass Company for providing samples for this study.

\section{Reference}

[1] Axinte E. Glasses as engineering materials: a review. Mater Des 2011; 32:1717-1732.

[2] Bandyopadhyay P, Mukhopadhyay AK. Role of shear stress in scratch deformation of soda-lime-silica glass. J Non-Cryst Solids 2013; 362: 101-113.

[3] Kolluru PV, Green DJ, Pantano CG, Muhlstein CL. Effects of surface chemistry on the nanomechanical properties of commercial float glass surfaces. J Am Ceram Soc 2010; 93: 838-847.

[4] Cook LM. Chemical processes in glass polishing. J Non-Cryst Solids 1990; 120: 152-171.

[5] Tomozawa M, Cherniak D, Lezzi P. Hydrogen-to-alkali ratio in hydrated alkali aluminosilicate glass surfaces. J Non-Cryst Solids 2012; 358: 3546-3550.

[6] Le Houérou V, Sangleboeuf JC, Dériano S, Rouxel T, Duisit G. Surface damage of soda-lime-silica glasses: indentation scratch behavior. J Non-Cryst Solids 2003; 316: 54-63.

[7] Wiederhorn SM. Influence of water vapor on crack propagation in soda-lime glass. J Am Ceram Soc 1967; 50: 407-714.

[8] Bradley LC, Dilworth ZR, Barnette AL, Hsiao E, Barthel AJ, Pantano CG, Kim SH. Hydronium ions in soda-lime silicate glass surfaces. J Am Ceram Soc 2013; 96: 458-463.

[9] He H, Qian L, Pantano CG, Kim SH. Mechanochemical wear of soda lime silica glass in humid environments. J Am Ceram Soc 2014; 97: 2061-2068. 
[10] Surdyka ND, Pantano CG, Kim SH. Environmental effects on initiation and propagation of surface defects on silicate glasses: scratch and fracture toughness study. Appl Phys A 2014; 116: 519-528.

[11] He H, Qian L, Pantano CG, Kim SH. Effects of humidity and counter-surface on the tribochemical wear of soda-lime-silica glass. Wear 2015; 342-343: 100-106.

[12] Pagnouxa G, Fouvry S, Peigney M, Delattre B, Mermaz-Rollet G. A model for single asperity perturbation on lubricated sliding contact with DLC-coated solids. Tribol Int 2015; 82: $423-430$.

[13] Yu J, Hu H, Jia F, Yuan W, Zang H, Cai Y, Ji F. Quantitative investigation on single-asperity friction and wear of phosphate laser glass against a spherical AFM diamond tip. Tribol Int 2015; 81: 43-52.

[14] Rhee TH, Shin MW, Jang H. Effects of humidity and substrate hydrophilicity on nanoscale friction. Tribol Int 2016; 94: 234-239.

[15] Stevens F, Langford SC, Dickinson JT. Tribochemical wear of sodium trisilicate glass at the nanometer size scale. J Appl Phys 2006; 99: 023529.

[16] Yu J, Yuan W, Hu H, Zang H, Cai Y, Ji F. Nanoscale friction and wear of phosphate laser glass and $\mathrm{BK} 7$ glass against single $\mathrm{CeO}_{2}$ particle by AFM. J Am Ceram Soc 2015; 98 : $1111-1120$.

[17] Mostofa M, Park C, Park S. AFM probe based nano mechanical scribing of soda-lime glass. J Manufacturing Processes 2013; 15: 625-634.

[18] Mauro JC, Philip CS, Vaughn DJ, Pambianchi MS. Glass science in the united states: current status and future directions. Inter J Appl Glass Sci 2014; 5: 2-15. 
[19] Wang X, Song C, Yu B, Chen L, Qian L. Nanowear behaviour of monocrystalline silicon against $\mathrm{SiO}_{2}$ tip in water. Wear 2013; 298: 80-86.

[20] Song C, Li X, Cui S, Dong H, Yu B, Qian L. Maskless and low-destructive nanofabrication on quartz by friction-induced selective etching. Nanoscale Res Lett 2013; 8: 140.

[21] Yu B, Li X, Dong H, Chen Y, Qian L, Zhou Z. Towards a deeper understanding of the formation of friction-induced hillocks on monocrystalline silicon. J Phys D Appl Phys 2012; 45: 145301.

[22] Yu J, Kim SH, Yu B, Qian L, Zhou Z. Role of tribochemistry in nanowear of single-crystalline silicon. ACS Appl Mater Interfaces 2012; 4: 1585-1593.

[23] Barthel AJ, Kim SH. Lubrication by physisorbed molecules in equilibrium with vapor at ambient condition: effects of molecular structure and substrate chemistry. Langmuir 2014; 30: 6469-6478.

[24] Marchand DJ, Chen L, Meng Y, Qian L, Kim SH. Effects of vapor environment and counter-surface chemistry on tribochemical wear of silicon wafers. Tribol Lett 2014; 53: $365-372$.

[25] Ciccotti M. Stress-corrosion mechanisms in silicate glasses. J Phys D Appl Phys 2009 42: 214006.

[26] Yue D, Ma TB, Hu Y, Yeon J, van Duin AC, Wang H, Luo J. Tribochemical mechanism of amorphous silica asperities in aqueous environment: a ReaxFF molecular dynamics study. Langmuir 2015; 31: 1429-1436.

[27] Johnson KL. Contact mechanics; Cambridge University Press: Cambridge, U.K. 1985. 
[28] Hagan J. Shear deformation under pyramidal indentations in soda-lime glass. J Mater Sci $1980 ; 15$ (6) 1417-1424.

[29] Amma S, Luo J, Pantano CG, Kim SH. Specular reflectance (SR) and attenuated total reflectance (ATR) infrared (IR) spectroscopy of transparent flat glass surfaces: A case study for soda lime float glass. J Non-Cryst Solids 2015; 428: 189-196.

[30] Michalske TA, Bunker B. Slow fracture model based on strained silicate structures. J Appl Phys 1984; 56: 2686-2693.

[31] Zhu T, Li J, Lin X, Yip SJ. Stress-dependent molecular pathways of silica-water reaction. Mech Phys Solids 2005; 53: 1597-1623.

[32] Kopta S, Salmeron M. The atomic scale origin of wear on mica and its contribution to friction. J Chem Phys 2000; 113: 8249-8252.

[33] Bennewitz R, Dickinson J. Fundamental studies of nanometer-scale wear mechanisms. MRS bulletin 2008; 33: 1174-1180. 


\section{Figures captions list}

Figure 1. (a) Illustration of the nanowear test of SLS glass using AFM. (b) SEM images of (i) $\mathrm{SiO}_{2}$ tip and (ii) diamond tip used in this study.

Figure 2. The AFM images and characteristic line profile of nanowear track at SLS glass made by a diamond tip in vacuum conditions in various normal load conditions. (a) $20 \mu \mathrm{N}$, (b) $30 \mu \mathrm{N}$, (c) $40 \mu \mathrm{N}$. D = $500 \mathrm{~nm}, \mathrm{v}=2 \mu \mathrm{m} / \mathrm{s}, \mathrm{N}=400$.

Figure 3. The AFM image and characteristic line profile of nanowear track at SLS glass made by a diamond tip in $40 \% \mathrm{RH}$ conditions in various normal load conditions. (a) $5 \mu \mathrm{N}$, (b) 10 $\mu \mathrm{N}$,(c) $20 \mu \mathrm{N}$,(d) $30 \mu \mathrm{N}$. D = $500 \mathrm{~nm}, \mathrm{v}=2 \mu \mathrm{m} / \mathrm{s}, \mathrm{N}=400$.

Figure 4. The AFM image and characteristic line profile of nanowear track at SLS glass made by a silica tip in $40 \% \mathrm{RH}$ under various load conditions. (a) $1 \mu \mathrm{N}$, (b) $1.5 \mu \mathrm{N}$,(c) $2 \mu \mathrm{N}$, (d) 3 $\mu \mathrm{N} . \mathrm{D}=500 \mathrm{~nm}, \mathrm{v}=2 \mu \mathrm{m} / \mathrm{s}, \mathrm{N}=400$.

Figure 5. Comparison of friction coefficient when rubbing against (a) diamond tip and (b) silica tip.

Figure 6. The schematic diagram of nanowear process on SLS glass substrate due to (a) stress corrosion due to water; (b) interfacial reactions involving the counter-surface and water.

Figure 7. Effect of contact pressure on the wear volume of SLS glass by various RH and counter-surface materials. The negative wear volume is surface protrusion (hillock) and the positive volume is material removal.

Figure 8. Correlation of wear rate and dissipated energy in various conditions. The negative wear volume is surface protrusion (hillock) and the positive volume is material removal. 
Figure 1

AFM probe

(i)

$1 \mu \mathrm{m}$

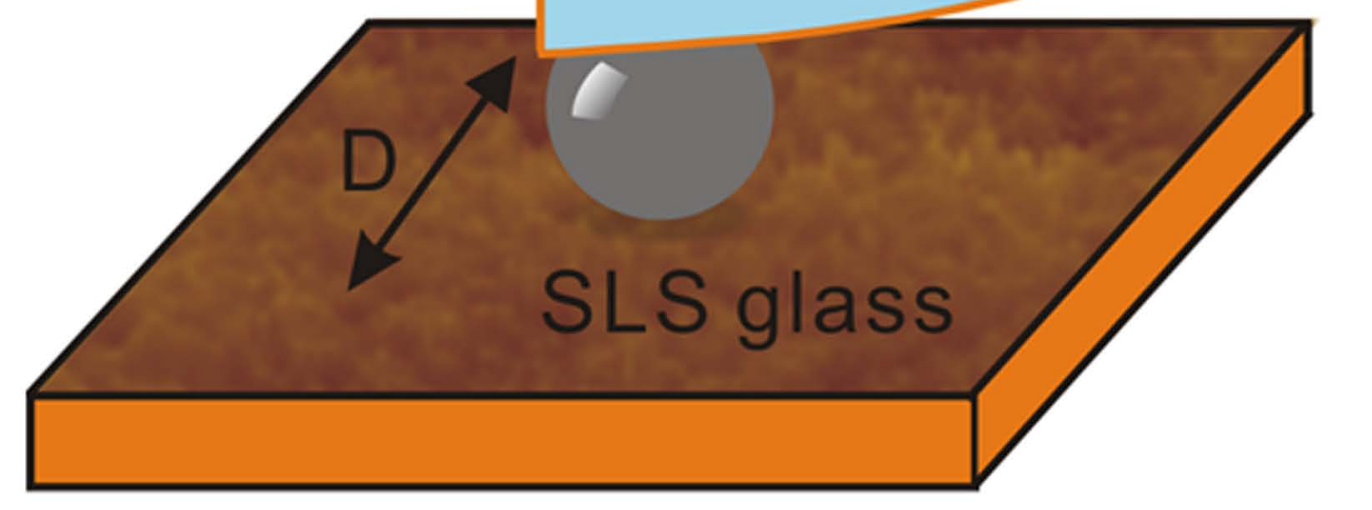

(ii)

(a)

(b) 
Figure 2

$500 \mathrm{~nm}$
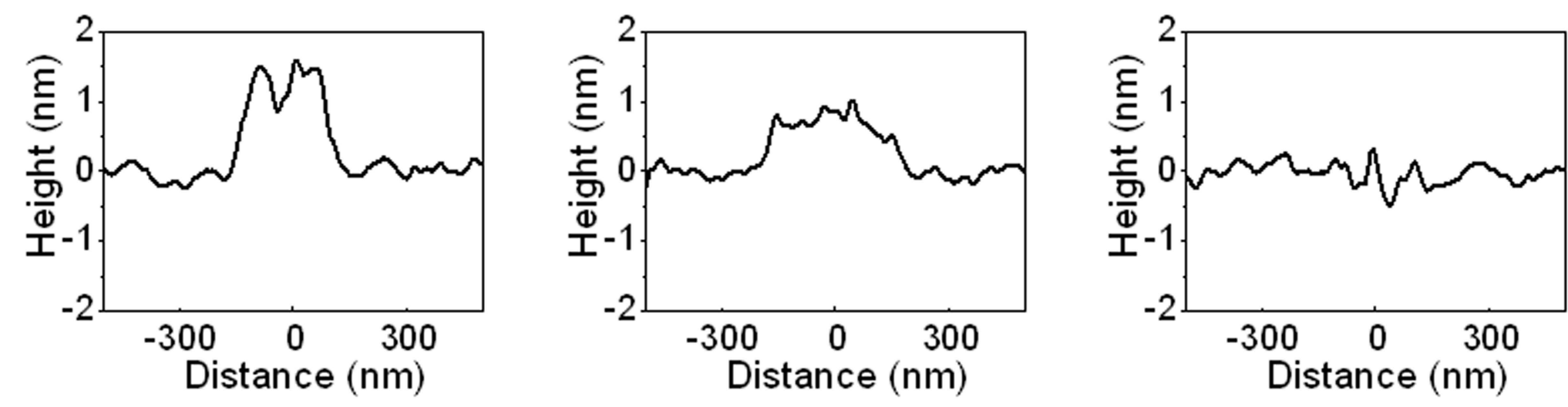

(a)

(b)

(c) 

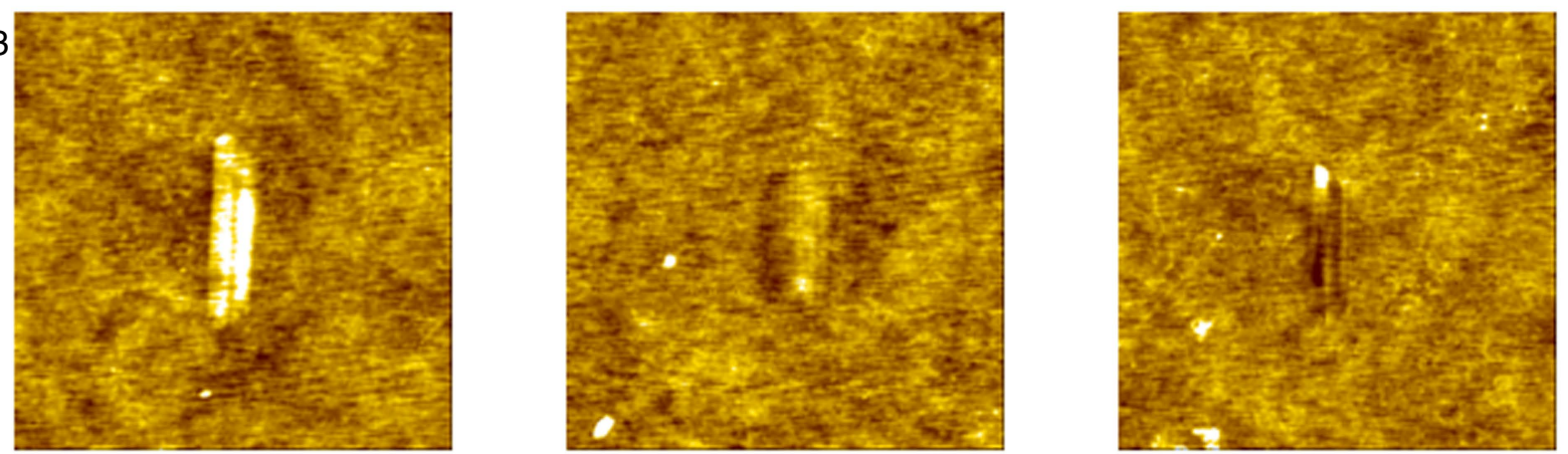

$500 \mathrm{~nm}$
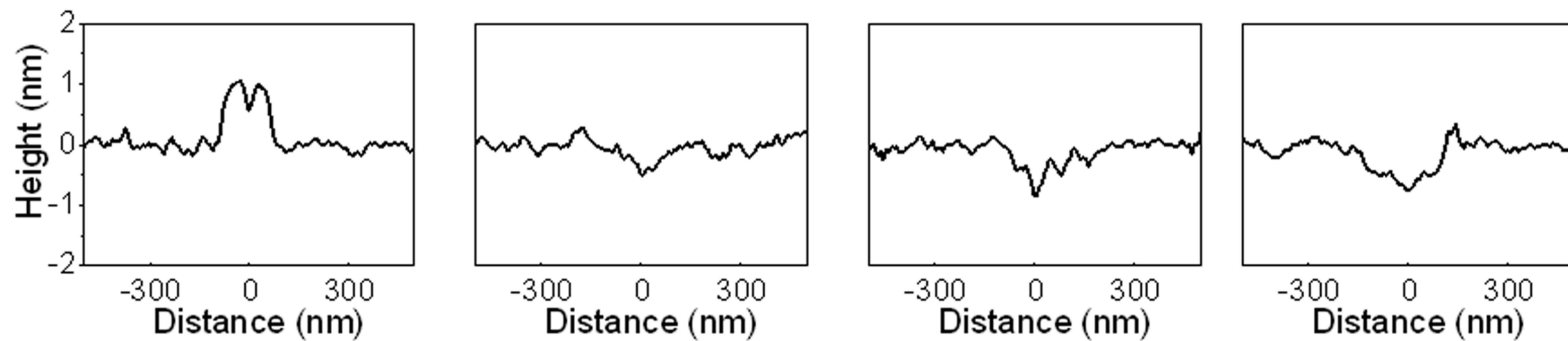

(a)

(b)

(c)

(d) 

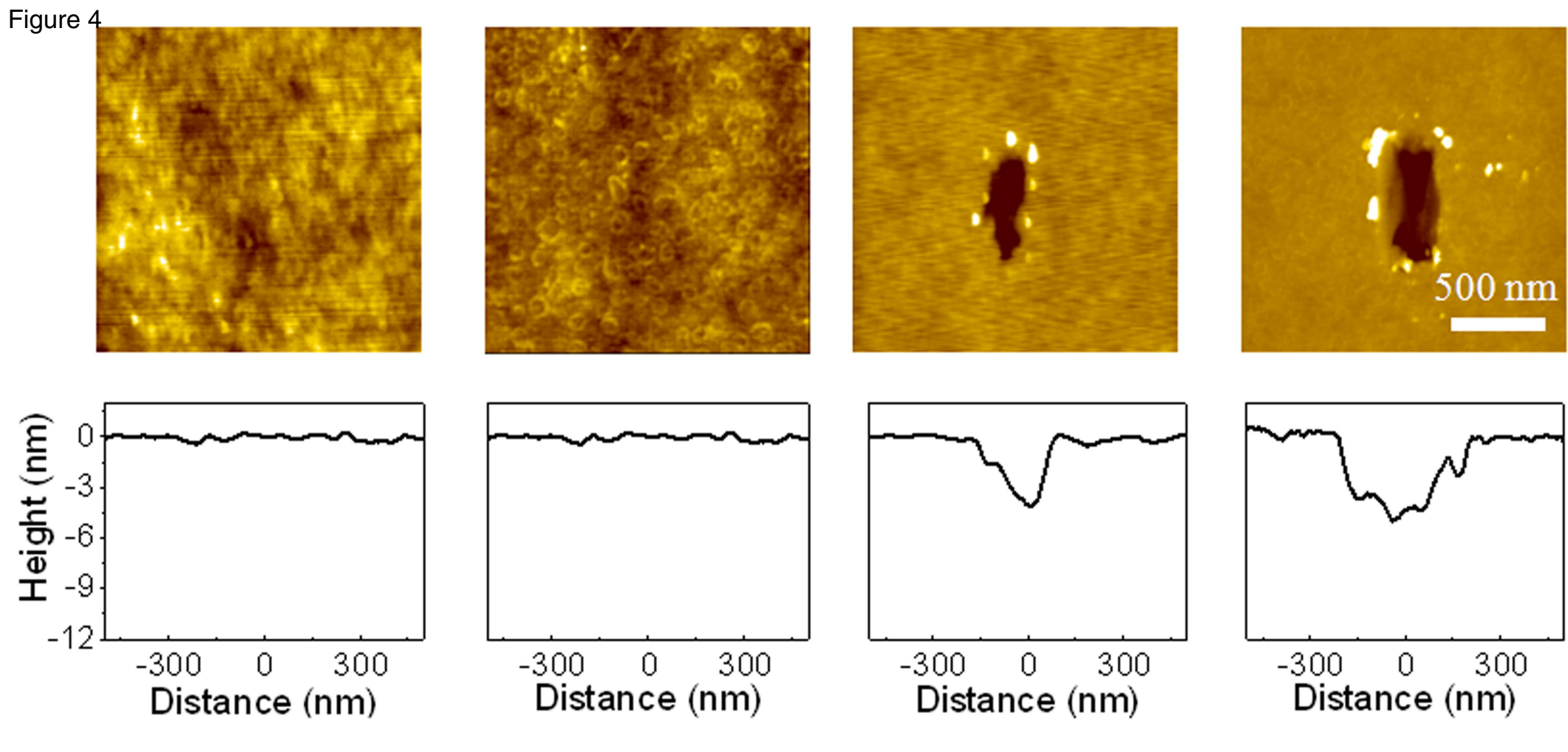

Distance $(\mathrm{nm})$
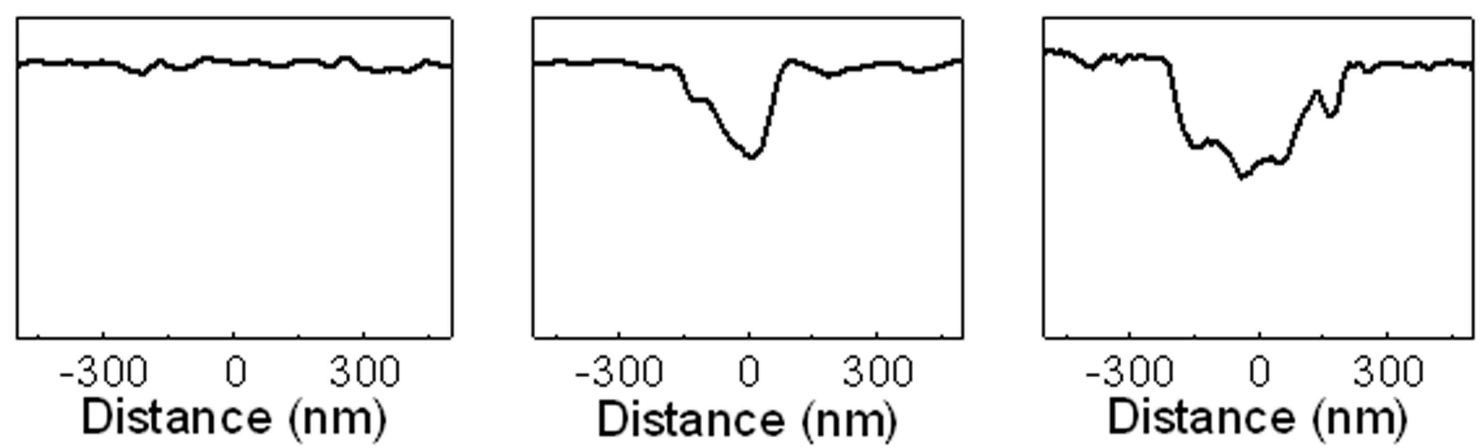

(a)

(b)

(c)

(d)

- 
Figure 5

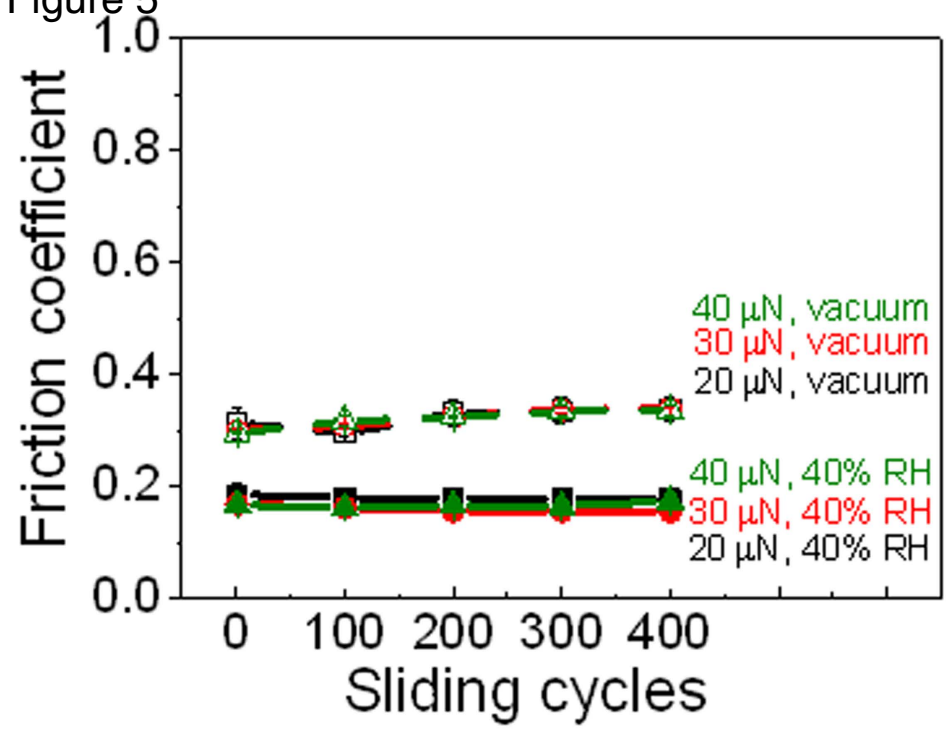

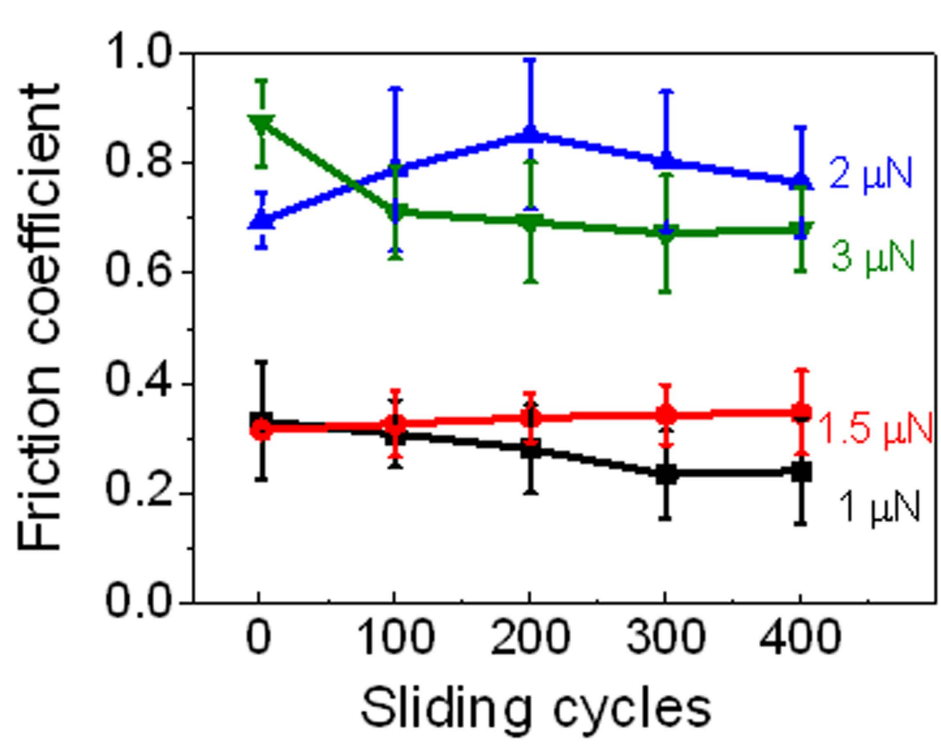

(a) (b) 


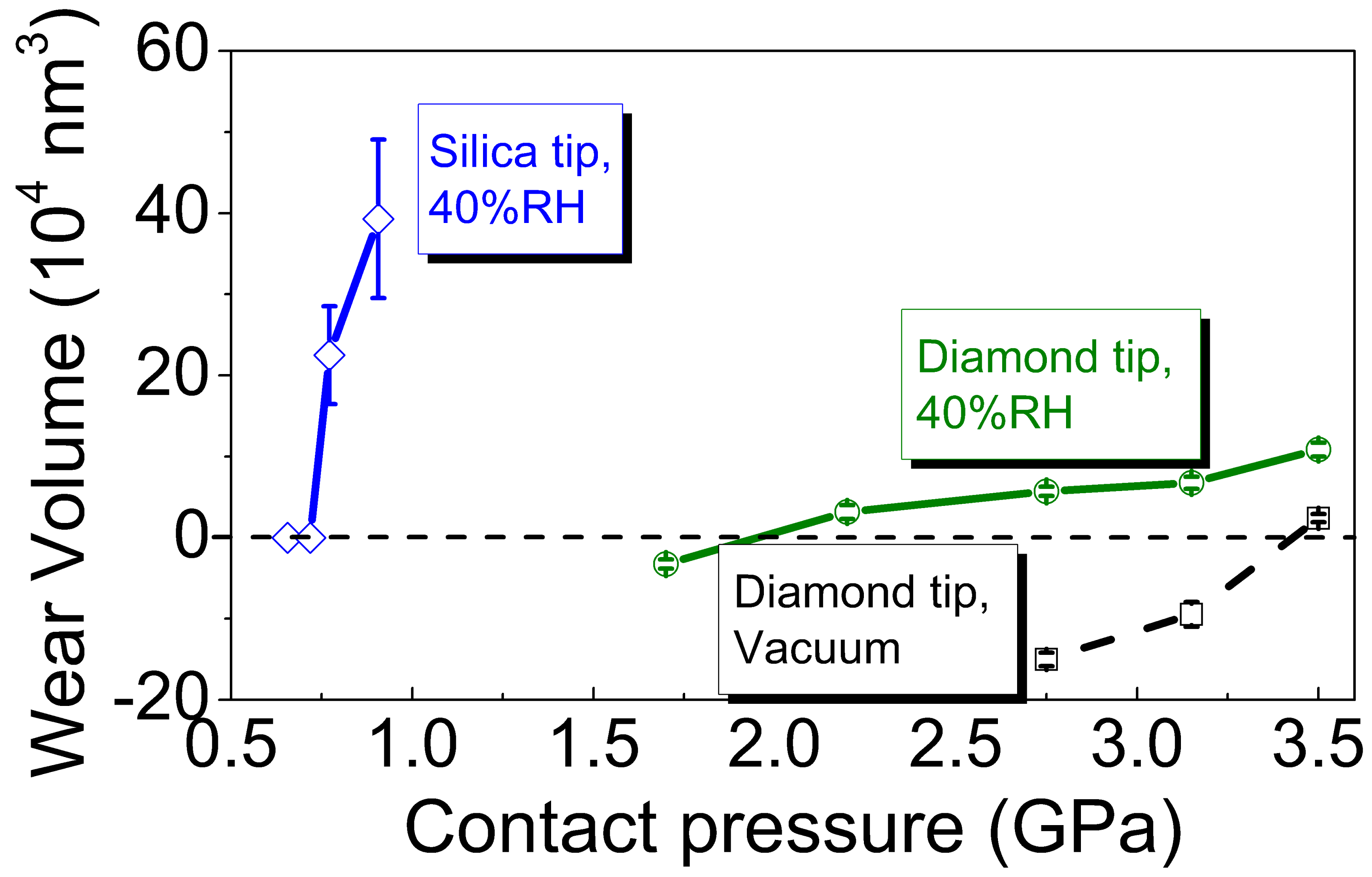




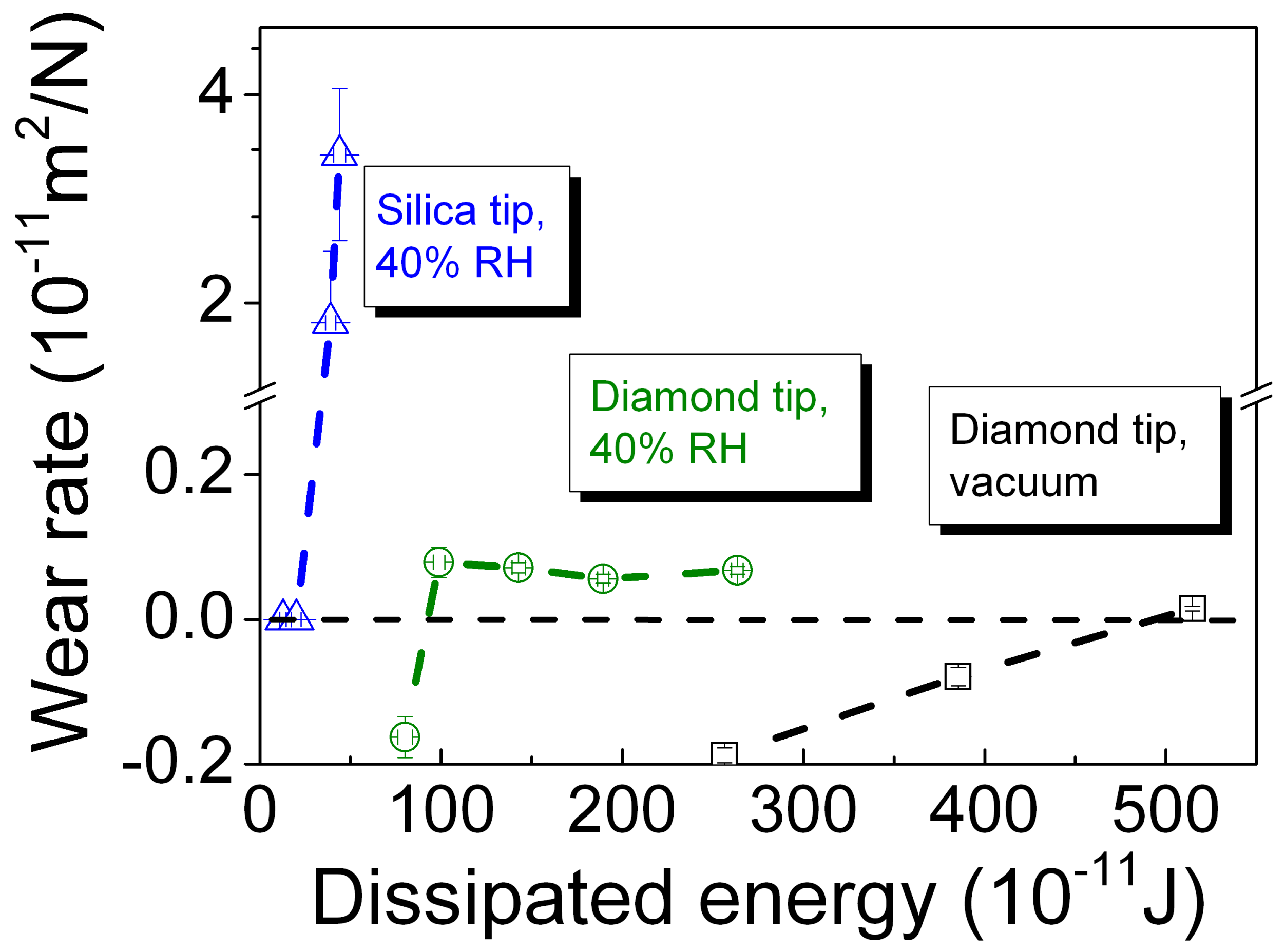


Table 1. Comparison of experiments conditions tested in this work.

\begin{tabular}{ccc}
\hline Experiment conditions & Reactive tip & Reactive gas \\
\hline Diamond tip, vacuum & $\times$ & $\times$ \\
\hline Diamond tip, 40\%RH & $\times$ & $\sqrt{ }$ \\
\hline silica tip, $40 \% \mathrm{RH}$ & $\sqrt{ }$ & $\sqrt{ }$ \\
\hline
\end{tabular}

